Supporting information to

\title{
Probing Thermal Stability of Proteins with Temperature Scanning Viscometer
}

Bowen Jiang, Amita Jain, Yuwei Lu, and Stephen W. Hoag*

Department of Pharmaceutical Sciences, University of Maryland, Baltimore, MD 21201

Table of contents:

Supplementary Experimental Procedures

Supplementary Figure

Supplementary Table 


\section{Supplementary Experimental Procedures}

Figure S-1. Second derivative UV-Vis spectrum of BSA. A peak around $284 \mathrm{~nm}$ was assigned to combination of Tyrosine and Tryptophan.

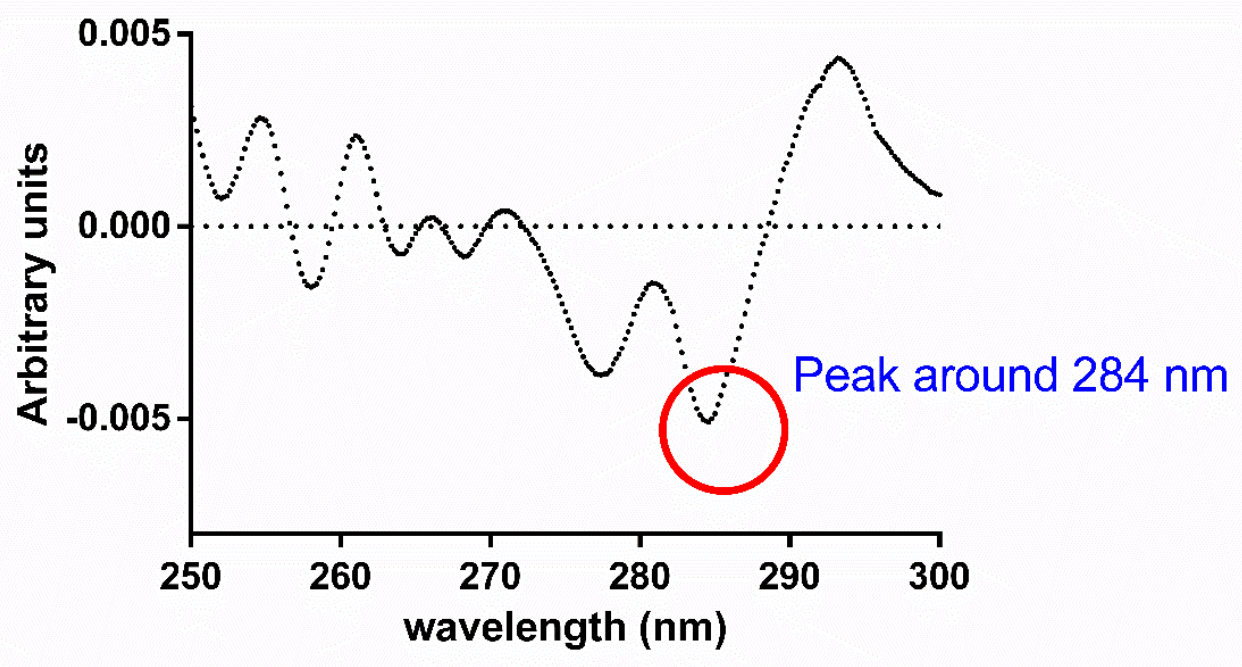


Table S-1. Excipients effects on the melting temperature of BSA.

\begin{tabular}{cccccc}
\hline Protein & $\begin{array}{c}\text { Concentration } \\
(\mathrm{mg} / \mathrm{mL})\end{array}$ & $\begin{array}{c}\text { Sucrose } \\
(\mathrm{w} / \mathrm{w} /)\end{array}$ & $\mathrm{Tm}$ & $\mathrm{SD}$ & $\mathrm{RSD}$ \\
\hline \multirow{6}{*}{$\mathrm{BSA}$} & $0 \%$ & 63.4 & 1.37 & $2.17 \%$ \\
& 1 & $10 \%$ & 66.2 & 1.02 & $1.54 \%$ \\
& \multirow{3}{*}{1} & $30 \%$ & 69.9 & 2.00 & $2.86 \%$ \\
& & $\mathrm{GdnHCl}(\mathrm{M})$ & $\mathrm{Tm}$ & $\mathrm{SD}$ & $\mathrm{RSD}$ \\
& & 0.5 & 53.8 & 4.1 & $7.7 \%$ \\
& & 1 & 44.5 & 0.4 & $0.9 \%$ \\
& & 2 & n.a. & n.a. & n.a \\
\hline
\end{tabular}

